\title{
Paraganglioma in supraglottic area: A rare case report
}

\author{
Dr.Shilpi Sahu ${ }^{1}$,Dr. Ujwala Maheshwari ${ }^{2}$,Dr.Ritika Jaiswal ${ }^{3}$ \\ ${ }^{\text {I}}$ (Pathology department, Mahatma Gandhi Medical College ad Hospital, India) \\ ${ }^{2}$ (Pathology department, Mahatma Gandhi Medical College ad Hospital, India) \\ 3(Pathology department, Mahatma Gandhi Medical College ad Hospital, India)
}

\begin{abstract}
Paragangliomaof the larynx is a rare tumourthat arises from paraganglion cells. These tumors are generallyconsidered benign and have to be differentiated from other neuroendocrine tumors. Diagnosis relies mostly on histopathological examination followed by immunohistochemistry. Surgical excision generally confers complete cure of the tumor. We hereby present a case of laryngeal paragangliomain a 50yearoldfemale, who presented with breathlessness, underwent total laryngectomy following a diagnostic microlaryngeal biopsy, which was supported by immunohistochemistry.
\end{abstract}

Keywords- Immunohistochemistry; Larynx; Neuroendocrine; Paraganglioma

\section{Introduction:}

Paragangliomas of the head and neck are slow-growing, highly vascular tumours arising from groups of cervical paraganglia. The most common cervical paraganglioma arises from theintercarotidparaganglia and very rarely the laryngeal paraganglia ${ }^{1}$.Approximately $90 \%$ of tumours arising from the paraganglion system are in the adrenal gland. The remaining $10 \%$ arise from extra-adrenal sites with $85 \%$ arising in the abdomen, $12 \%$ in the thorax and the remaining $3 \%$ in the head and neck region. ${ }^{2}$ Thecarotid body is the most frequently reported site of paragangliomain the head and neck region. They are a subclass of neuroendocrine tumors of the larynx with a neural origin. The other subclass of neuroendocrine tumors are of epithelial origin and include typical carcinoids, atypical carcinoids and small cell neuroendocrine carcinoma ${ }^{3}$. Paragangliomas of the laryngopharynx are rare tumors that are of neuroendocrine origin and arise from the neural crest-derived cells of the parasympathetic nervous system. Since its first description in the literature in 1955, fewer than 80 such cases have been reported ${ }^{4}$. Patients present with hoarseness or dysphasia, and a submucosalmassis evident on physical examination. The majority of these tumors arise in the supraglottic larynx, and $2 \%$ of these are malignant ${ }^{4-6}$. Since these tumors are from neural crest-derived cells, they usually appear adjacent to nervestructures, most commonly the superior laryngeal nerve or the recurrent laryngeal nerve ${ }^{7}$.

\section{Case Report:}

A 50-year-old woman presented with breathlessness since 1 year and hoarseness of voice and for six months. She was hypertensive. Fibreoptic laryngoscopy revealed a pink exophytic mass arising from epiglottis, right aryepiglottic fold and false cord compromising glottis fold and pushing the epiglottis to the left side. MRI was done which suggested a moderately enhancing vascular tumorof laryngopharynx in supraglottic region measuring $3.7 \times 3.2 \mathrm{cms}$ well above the vocal cord.

Laryngeal biopsy was sent .Microscopic examination oflaryngealbiopsy revealedsubmucosaltumor composed of atypical cells arranged in nests and lobules separated by fibrovascularstroma. The tumor cells exhibited moderate pleomorphism with round to oval hyperchromatic nuclei. Cytoplasm wasmoderate to abundant, eosinophilic and granular. Congested capillaries and large areas ofhaemorrhage were noted. With these histopathologic findings, a provisional diagnosis of paraganglioma with the differential diagnosis of carcinoid tumor was made.Subsequently, the patient underwent an elective total laryngectomy and the specimen was sent for histopathological examination. Gross examination revealed a single grey brown soft to firm tissue mass measuring $3 \times 2 \times 1.8 \mathrm{~cm}$, external surface-congested .On cutting open-solid grey brown hetrogenous areas seen with few areas of congestion .Microscopic examination showed a subepithelialtumor composed of chief cells arranged in nests and characteristic zell-ballen pattern of variable sizes, separated by fibrovascularstroma (Fig. 1) and also in diffuse sheets in few areas separated by stag-horn vessels ( hemangio-pericytomatous pattern ). The chief cells were round to oval in shape with moderate to abundant amount of eosinophilic cytoplasm having nuclearpleomorphism with round to oval nuclei and granular to fine stippled chromatin (Fig 3 ). The sustentacular cells were located at the periphery of zellballen and had eosinophilic cytoplasm and angulated nuclei. Some cells showed bizzare nuclei and smudgy chromatin. (Fig 4).Large areas of hemorrhage and congestion were noted. Lymphovascular and perineural invasion was not seen. The surgical margins were free of tumor. Special stains were done like Reticulin stain - showing the zell-ballen pattern (Fig 2). 
Immunohistochemistry for cytokeratin and S100 (Fig5a\&b) was done in the tissue section which revealed S100positivity for sustantecularcells and cytokeratin negativity. A final diagnosis of paraganglioma was made.

\section{Discussion:}

Paragangliomas of the laryngopharynx are rare tumors that are of neuroendocrine origin and arise from the neural crest-derived cells of the parasympathetic nervous system.Laryngeal paragangliomas are three times more common in women and have been described in patients from 5-83 years of age (median 44 years). The vast majority $(82 \%)$ occur in the supraglotticlarynx, presumably arising from the superior pair of laryngeal paraganglia, and present as a submucosal mass in the region of the aryepiglottic fold- false vocal cord. Only $15 \%$ occur in the subglottis and 3\% in the glottis. The right side of the larynx is more often involved than the left by a ratio $2.3: 1^{8,9}$. Microscopically, laryngeal paragangliomas have the same appearance as paragangliomas of other sites. The tumor is highly vascular and composed of two types of cells: chief cells and sustentacular cells, arranged in a characteristic alveolar or Zellballen pattern. The chief cells (type Icells, epithelioid cells) are more numerous and contain catecholamine bound neurosecretory granules as seen ultrastructurally. The sustentacular cells (type II cells, supporting cells) are devoid of neurosecretory granules and are characteristically located at the periphery of Zellballen.The "Zellballen" pattern is not diagnostic of a paragangiomaas it may also exist in a variety of other tumors including typical and atypical carcinoid, malignant melanoma and medullary carcinoma of thyroid. Immunohistochemistry is helpful in establishing the correct diagnosis as the distinction between paraganglioma and atypical carcinoid neuroendocrine carcinoma may prove difficult on light microscopy. The presence of chromogranin positivity excludes non neuroendocrine neoplasms and the absence of keratin positivity and presence of S-100 protein-positivesustentacular cells tends to exclude carcinomas $^{10}$. In the present case, only a provisional diagnosis of paraganglioma could be made on histopathologic examination. However, with the help of immunohistochemistry (S100positive and Cytokeratin negative) a definitive diagnosis of paraganglioma was possible before surgical excision was performed. Paragangliomasare generally benign tumors. The presence of vascular, capsular or perineuralinvasion does not necessarily indicate aggressive behavior ${ }^{11}$. It is generallyaccepted that a paraganglioma is determined to bemalignantonly when metastasis is demonstrated ${ }^{12}$. We consider thepresent case to be benign as there was no evidence of metastasis. The patient is however under regular follow-up to detect any recurrence/metastasis at an early stage. The false cord area, while those arising in the inferiorparaganglia may present subglottically, intratracheally or adjacent to the thyroid gland. There has been a report of $2 \mathrm{~S}$ cases of laryngeal paraganglioma with 23 tumours occurring in the superior paraganglia and 2 arising from the inferior paraganglia ${ }^{13}$. These patients, as did our patient, presented with a compromised airway and phonation abnormalities. However, haemoptysis, neck discomfort and a mass in the neck have also been reported. ${ }^{14}$ All the reported cases presented with a wellcircumscribedsubmucosallaryngeal mass. Hence laryngeal paraganglioma should be considered in the differential diagnosis of all such masses.Surgical treatment of these tumours is indicated. Paragangliomasare radioresistant and the incidence of malignancy is high in laryngeal paragangliomas. Some authors ${ }^{15-17}$ have suggested that laryngeal paragangliomas have the highest incidence of malignancy in the extra-adrenal paraganglioma group. They reported that $24 \%$ of laryngeal paragangliomas followed a malignant course, with both local and distant metastases in the form of subcutaneous nodules. Our patient, and the majority of cases reported underwenta partial laryngectomy, however regular follow up is essential to detect any recurrence/metastasis at an early stage.

\section{Conclusion:}

Paraganglioma of larynx is rare. It has to be differentiated from other neuroendocrine tumors. The closest differential diagnosis for laryngeal paraganglioma is carcinoid tumor.. Diagnosis is based on its characteristic histopathologic findings, supported by immunohistochemistry. Laryngopharyngealparagangliomas are uncommon tumors that are conventionally treated with surgical resection for oncologic control. Close collaboration with an experienced pathologist is necessary to establish the diagnosis with immunohistochemical evaluation and electron microscopy to confirm the diagnosis. Surgical resection remains thestandard of care for their treatment, although radiotherapy may be considered in selected patients. Although malignant paragangliomas of the larynxhave been reported, they are rare and metastasis should raise the question of misdiagnosis. 
Figure legends : -

\begin{tabular}{|l|l|l|}
\hline Figure 1 & H \& E stained section (40 X) & $\begin{array}{l}\text { Showing subepithelialtumor } \\
\text { composed of chief cells arranged in } \\
\text { nests and characteristic zellballen } \\
\text { pattern of variable sizes, separated } \\
\text { by fibrovascularstroma }\end{array}$ \\
\hline Figure 2 & Reticulin stain (40 X) & $\begin{array}{l}\text { Showing the enhanced zell-ballen } \\
\text { pattern }\end{array}$ \\
\hline Figure 3 & H \& E stained section (40 X) & $\begin{array}{l}\text { Showing round to oval chief cells } \\
\text { with moderate to abundant amount } \\
\text { of eosinophilic cytoplasm having } \\
\text { nuclear pleomorphism with round } \\
\text { to oval nuclei and stippled } \\
\text { chromatin }\end{array}$ \\
\hline Figure 4 & H \& E stained section (40 X) & $\begin{array}{l}\text { Showing few cells having bizzare } \\
\text { nuclei and smudgy chromatin }\end{array}$ \\
\hline Figure 5 a & $\begin{array}{l}\text { Immunohistochemistry for S100 } \\
(10 X)\end{array}$ & $\begin{array}{l}\text { Showing S100 positivity for } \\
\text { sustantecular network surrounding } \\
\text { epithelioid nests }\end{array}$ \\
\hline Figure 5 b & $\begin{array}{l}\text { Immunohistochemistry for S100 ( } \\
40 \mathrm{X})\end{array}$ & $\begin{array}{l}\text { Showing S100 positivity for } \\
\text { sustantecular network surrounding } \\
\text { epithelioid nests }\end{array}$ \\
\hline
\end{tabular}

Figure : -

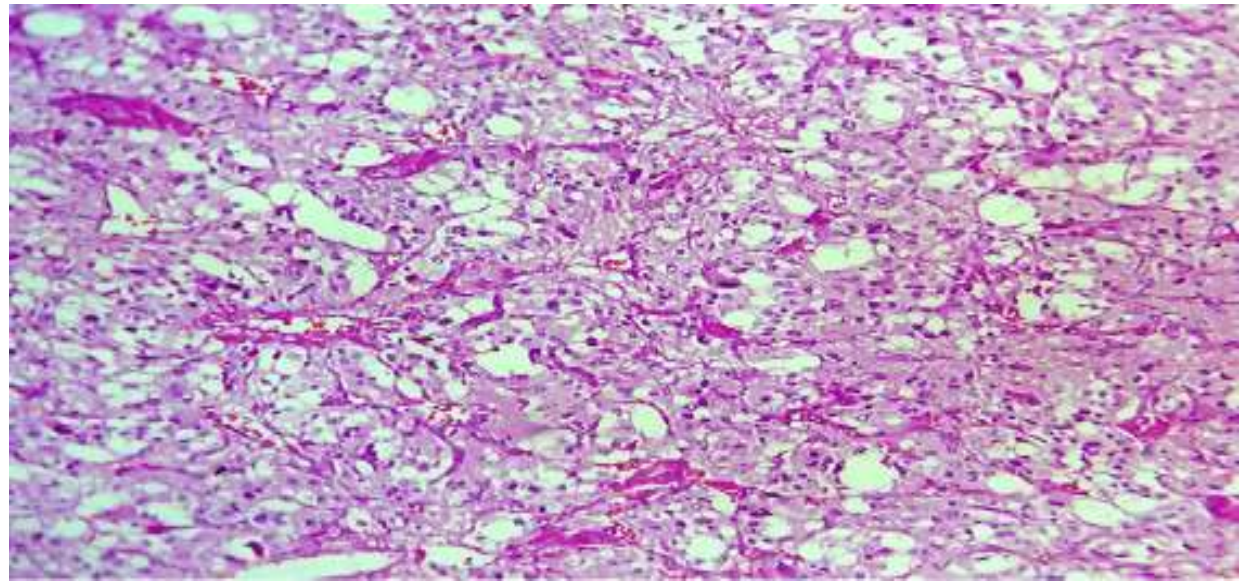

Figure 1

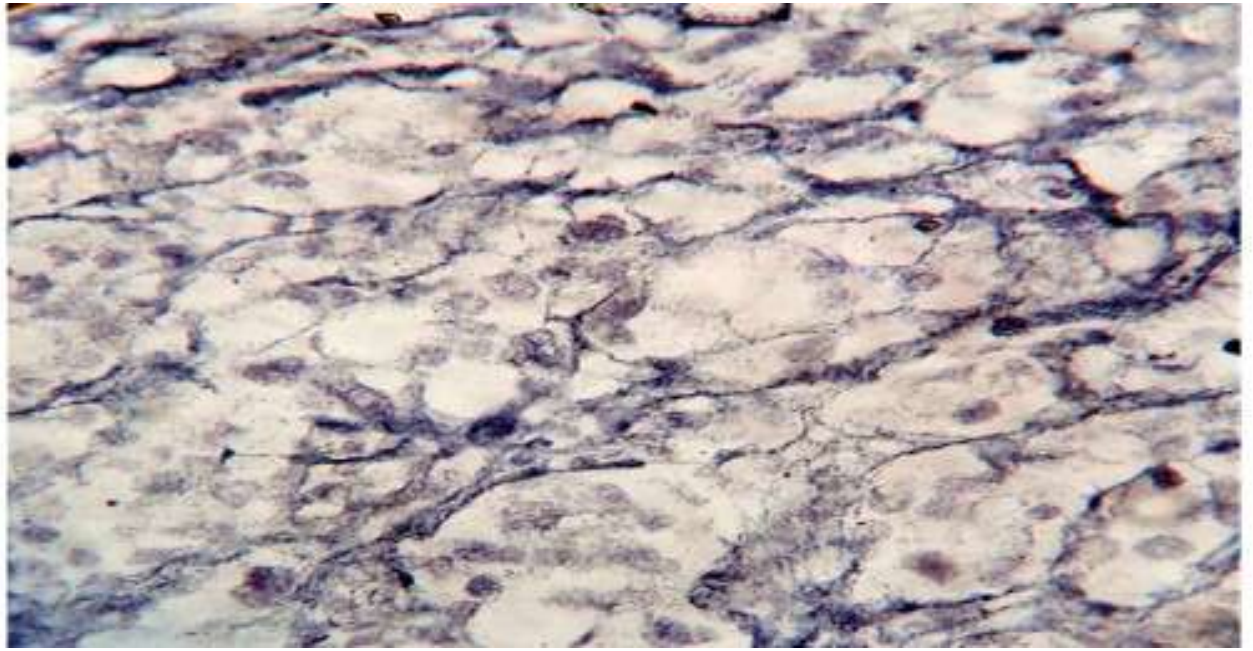

Figure 2 

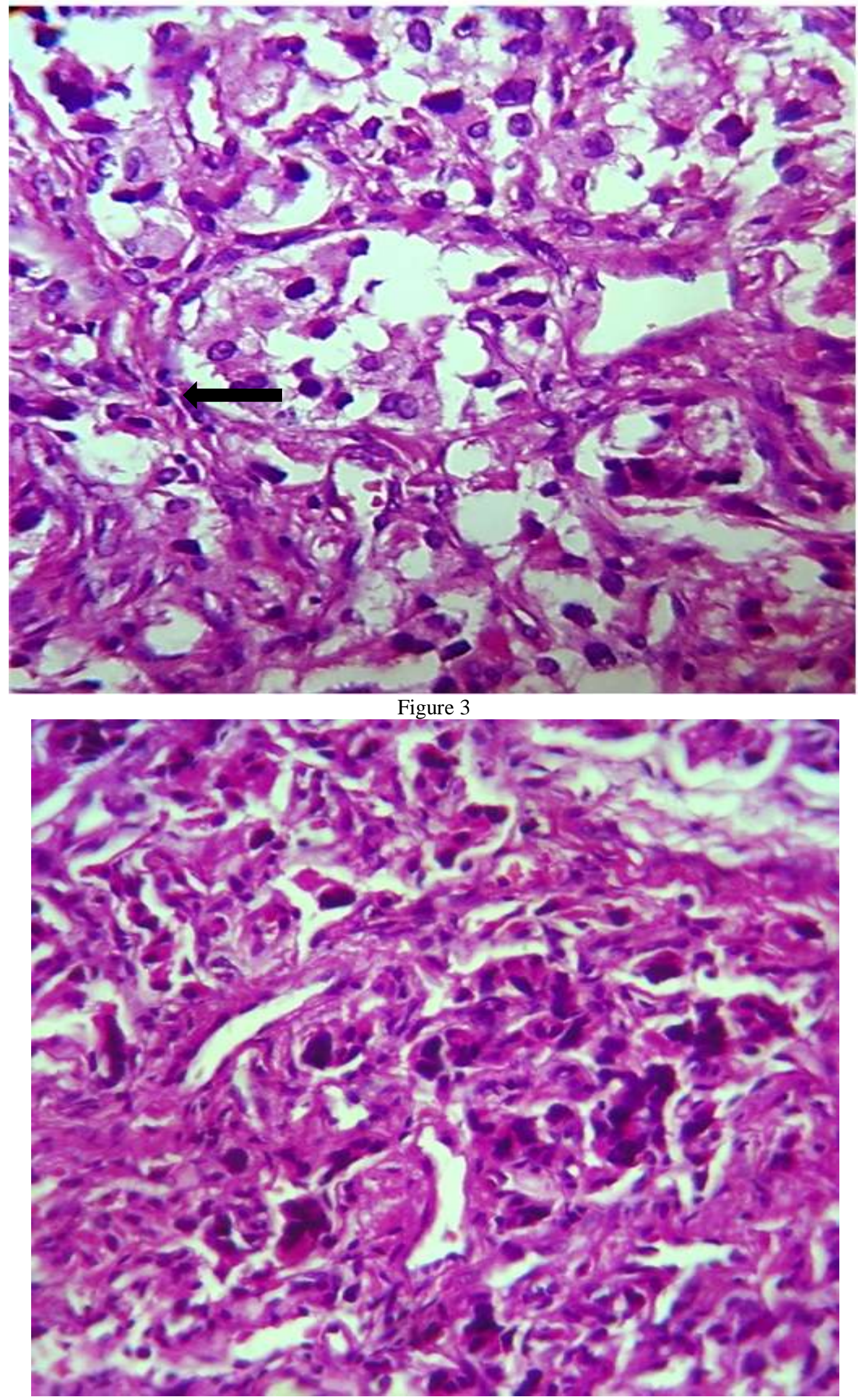

Figure 4 


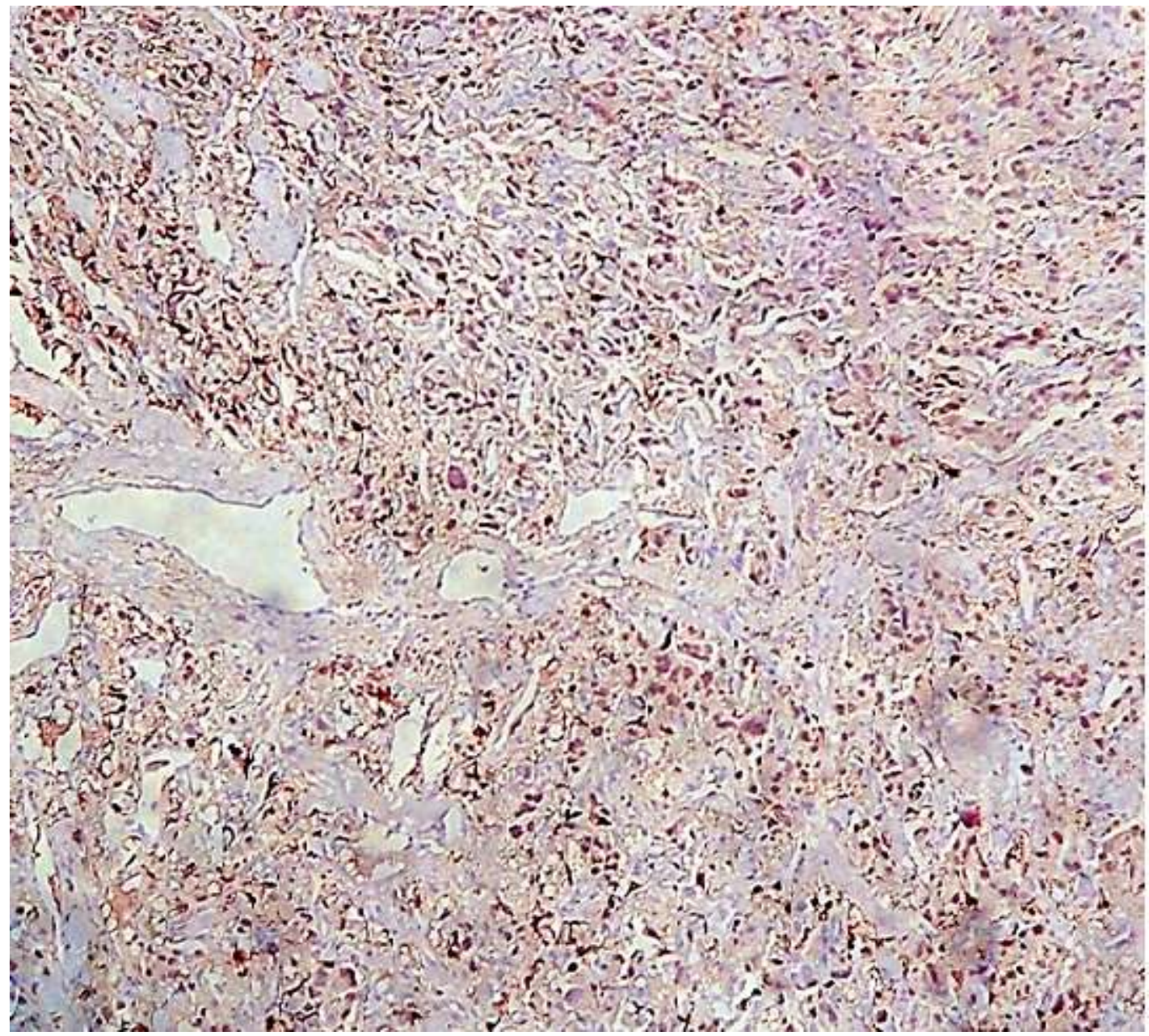

Figure 5 a

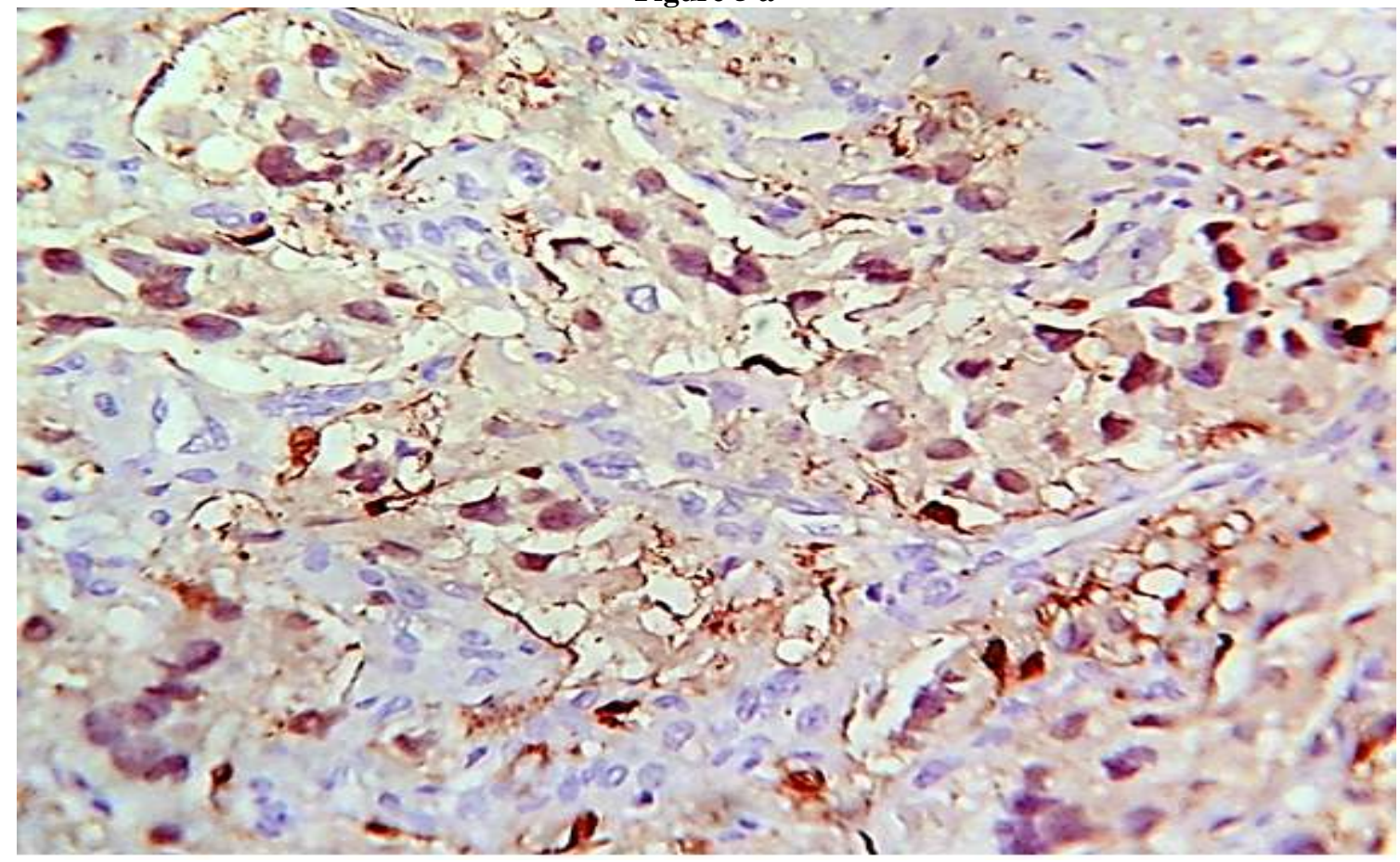

Figure 5 b 


\section{Acknowledgement:}

We would like to thanks ENT Department of Mahatma Gandhi Medical College and Hospitals for their logistic support.

\section{References:}

[1] Lack EE, Cubilla AC, Woodruff JM et al. Paragangliomas of the head and neck region. Cancer 1977; 39: $397-409$.

[2] Wasserman P, Savargaonkar P. Paragangliomas: Classification, Pathology, and Differential Diagnosis, Otolaryngol Clinics N Am2002;34:845-62.

[3] Gripp FM, Risse EKJ, Leverstein H, Snow GB, Meijer CJL. Neuroendocrine neoplasms of the larynx.Importance of the correct diagnosis and differences between atypical carcinoid tumours and small-cell neuroendocrine carcinoma.Eur Arch Otorhinolaryngol1995;252:280-6.

[4] Ferlito A, Barnes L, Wenig BM: Identification, classification, treatment, and prognosis of laryngeal paraganglioma. Review of the literature and eight new cases. Ann OtolRhinolLaryngol 1994, 103(7):525-36

[5] Myssiorek D, Rinaldo A, Barnes L, Ferlito A: Laryngeal paraganglioma: an updated critical review. ActaOtolaryngol 2004, 124(9):995-9.

[6] Barnes L: Paraganglioma of the larynx. A critical review of the literature.nORL J OtorhinolaryngolRelat Spec 1991, 53(4):220-34

[7] Batsakis JG, el-Naggar AK, Luna MA: Neuroendocrine tumors of larynx. Ann OtolRhinolLaryngol 1992, 101(8):710-4.

[8] 8.Ferito A, Barnes L, Wenig BM: Identification, classification, treatment, and prognosis of laryngeal paraganglioma. Review of the literature and eight new cases. Ann OtolRhinolLaryngol1994;103:525-36.

[9] Barnes L. Paraganglioma of the larynx. A critical review of the literature. ORL J OtorhinolaryngolRelat Spec 1991;53:220-34.

[10] Pilch BZ. Larynx and trachea; Benign neoplasms. In: Fletcher CDM, Diagnostic Histopathology of Tumors, 3rd Edn. Churchill Livingstone 2007.pp153.

[11] Ferlito A, Milory CM, Wenig BM et al. Laryngeal paraganglioma versus atypical carcinoid tumor. Ann OtolRhinolLaryngol1995;104:78-83.

[12] Kimura N, Chetty R, Capella C et al. Extra-adrenal paraganglioma: Carotid body, jugulotympanic, vagal, laryngeal, aorticopulmonary. In: DeLellis, Lloyd RV, Heitz PU, Eng C, Editors. Pathology and Genetics.Tumors of Endocrine Organs, Lyon: IARC Press, 2004. 16pp.

[13] Schaefer SO, Blend BL, Denton J. Laryngeal paragangliomas: evaluation and treatment. Am] Orolaryngol 1980; I: 451 -455.

[14] Vetlers JM, Tooer PG. Chemodectoma of larynx. J Parhol 1970; 101: 259-265.

[15] Adlingron P, Woodhouse M. The ultrastructure of chemodectoma of the laryID!.. J Laryngol OroI1972; 86: 1219-1232.

[16] Michaels L. Neurogenic tumors, granular cell tumors and paraganglioma. Can] Orolaryngol1975; 4: 319-327.

[17] Lack EE, Cubilla AL, Woodruff JM, Farr HW. Paragangliomas of the head and neck region: a clinical study of 69 patients. Cancer 1977; 39: 397-409. 